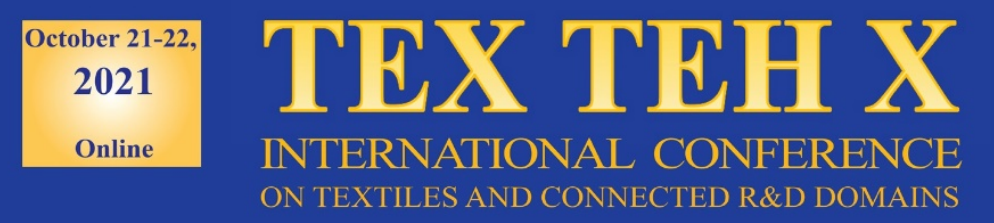

\title{
PARACETAMOL DRUG LOADED MICROCAPSULE BASED NANOFIBER PRODUCTION
}

\author{
DOI: $10.35530 /$ TT.2021.30
}

\author{
İ.Y. Mol ${ }^{1 *}$, F.C. Çallığglu ${ }^{1}$, H.K. Güler ${ }^{1}$, M. Geysoğlu ${ }^{2}$ \\ ${ }^{1}$ Textile Engineering Department, Engineering Faculty, Süleyman Demirel University, Turkey \\ (E-mail: iremyagmurmol@gmail.com, fundacengiz@sdu.edu.tr, hulyakesici@sdu.edu.tr) \\ ${ }^{2}$ Bioengineering Department, Institute of Natural and Applied Sciences, Süleyman Demirel University, \\ Turkey \\ (E-mail: mustafageysoglu@sdu.edu.tr)
}

\begin{abstract}
In this study, it was aimed to production and characterization of paracetamol (PCT) loaded microcapsules and microcapsule added electro spun PVA nanofibers. Eudragit RS 100 and PVA were used as the shell in the microcapsule structure, and PCT was used as the core material. First of all, the PCT loaded Eudragit RS 100/PVA microcapsules were produced by solvent evaporation method under the optimum process parameters. Then, properties such as conductivity, viscosity and surface tension of the microcapsule loaded PVA solution were measured and the effects of microcapsule concentration on the solution properties were determined. According to the solution results, while the viscosity increased with the microcapsule concentration, conductivity and surface tension did not change significantly except for the PVA-10 sample. After the electrospinning process, fibre morphology was determined by SEM and incorporation of microcapsules into the nanofibers was clearly demonstrated. It was calculated from the SEM images that average microcapsule size is $9.81 \mu \mathrm{m}$, average fibre diameter is $550 \mathrm{~nm}$ and fibre diameter uniformity coefficient is 1.025. Finally, the incorporation of PCT loaded microcapsules into the nanofibers was chemically confirmed by FT-IR analysis. It is thought that the results of this study will be useful for controlled drug release, especially in medical textiles.
\end{abstract}

Keywords: electrospinning, medical textile, microcapsule, nanofiber, paracetamol

\section{INTRODUCTION}

Microcapsules have become very popular in recent years, especially for the development of functional fabrics in the textile industry. With the microencapsulation technique, controlled/delayed release, masking of taste, odour and color, protection against UV, heat, oxidation, acids and bases, stabilization of volatile compounds, antibacterial, antimicrobial, long-term flaming, retardant, insect repellent and thermal insulation properties can be achieved on textile surfaces [1]. As the core material, volatile, drug-active substances, taste, odour, etc. substances can be microencapsulated [2]. Microcapsules can be produced by physical or chemical methods [3].

Eudragit RS 100 is a copolymer of ethyl acrylate, methyl methacrylate, and a small amount of methacrylic acid ester containing quaternary ammonium groups [4]. Eudragit RS 100 used in the shell material is an easy to use and process polymer in any form as aqueous dispersions, granules, organic solutions, powders or ready-to-use powders [5]. Eudragit RS 100 is a biocompatible, inexpensive, easily produced polymer with good stability. It is a common polymer that is insoluble in water and is often used as a wall material in extended-release microcapsules [6]. Eudragit RS 100 has a wide use in coating, 
that is, microencapsulation, of drug-active substances that do not dissolve in water [7]. The main ingredient, paracetamol (PCT), is an active drug substance with analgesic and antipyretic effects. Paracetamol is a white, odourless, crystalline powder. It has a bitter taste [8]. Although it is slightly soluble in water, its analgesic effect is milder than other new generation pain relievers, PCT was preferred in the study due to its safety and lack of side effects in the digestive system. Solvent evaporation method was chosen as the microcapsule production method. The emulsion/solvent removal method is the most common method used for microencapsulation of water-insoluble drugs [9]. In the solvent evaporation method, the production conditions such as mixing speed, mixing time, solvent ratio, solution concentration have a great influence on the microcapsule morphology [10]. In addition, the fact that drug-loaded microcapsules do not leak or crack after production makes this method even more advantageous. During the experiments, the production is simpler as the solvent can be evaporated quickly by itself, by temperature or by mixing, that is, there is no need for an extra addition to the system.

Nanofiber textiles are materials with high porosity and specific surface area, pore size smaller than 1 micrometre, have water vapor permeability and air permeability. Electrospinning is a simple, inexpensive, easy and fast process used to obtain micro-nano size fibres suitable for commercial production, suitable for spinning many different polymers [11]. The Poly (vinyl alcohol) (PVA) used is a biocompatible and biodegradable semi-crystalline polymer and has a very good ability to form fibrous materials. It is water soluble, has very good chemical resistance, physical and mechanical properties and flexibility. It shows excellent electro-absorbability in aqueous environments [12]. It is thought that PCT loaded microcapsule added nanofiber material produced for this study will have an important place for medical textiles.

\section{MATERIALS AND METHODS}

\subsection{Materials}

For microencapsulation process, Eudragit ${ }^{\circledR}$ RS 100 (Evonik Röhm GmbH) and Polyvinyl alcohol ( $\mathrm{Mn}=88,000,88 \%$ hydrolysed) were used as shell materials, paracetamol (PCT) (Atabay Kimya, Turkey) was used as a core material, chloroform (Iso Lab) and distilled water were used as solvents and Span20 (Sigma-Aldrich Corporation (St. Louis, MO, USA)) was used as a surfactant. During nanofiber production experiments, Polyvinyl alcohol ( $\mathrm{Mn}=88,000$, 88\% hydrolysed) was used as a main polymer and distilled water was used as a solvent. PVA polymer concentration was kept constant as $10 \mathrm{wt} \%$ and PCT loaded microcapsule concentration was applied as $0,2,4,6$, 8,10 .

\subsection{Methods}

Microencapsulation was achieved by solvent/evaporation method which is the simple and physical method. In this method, the polymer is first dissolved with the solvent. Then the active ingredient is added. The dissolved polymer formed the oil phase, that is, the droplet phase. The surfactant forms the second and continuous phase by mechanical mixing in an aqueous solution. The polymer solution containing the insoluble substance from these two solutions was added to the droplets in the aqueous solution high speed mixer. Finally, the solvent is evaporated by mechanical action. The resulting microcapsules are washed with water, filtered with filter paper and dried. Composition of microcapsule loaded PVA solutions is given in table 1. 
Table 1. Composition of microcapsule loaded PVA polymer solutions

\begin{tabular}{|c|c|c|}
\hline Sample codes & $\begin{array}{c}\text { PVA concentration } \\
\text { (wt \%) }\end{array}$ & $\begin{array}{c}\text { Microcapsule concentration } \\
\text { (wt \%) }\end{array}$ \\
\hline PVA-0 & 10 & 0 \\
\hline PVA-2 & 10 & 2 \\
\hline PVA-4 & 10 & 4 \\
\hline PVA-6 & 10 & 6 \\
\hline PVA-8 & 10 & 8 \\
\hline PVA-10 & 10 & 10 \\
\hline
\end{tabular}

First of all, microcapsule loaded PVA solution properties such as conductivity, viscosity (shear rate $5 \mathrm{~s}^{-1}$ ) and surface tension were measured. Then, nanofiber production was carried out by conventional electrospinning method under the same process parameters. During the spinning process, $21.7 \mathrm{kV}$ voltage, $1.5 \mathrm{ml} / \mathrm{h}$ solution feed rate and $18.1 \mathrm{~cm}$ distance between the electrodes, $29 \pm 2 \%$ humidity and, $25.9 \pm 2{ }^{\circ} \mathrm{C}$ ambient conditions were applied for all solutions. All nanofibers were produced for 15 minutes and collected on aluminium foil. Microcapsules and nanofiber morphology such as capsule size, fibre diameter, diameter uniformity and nanoweb quality were analysed by Scanning Electron Microscopy (SEM).

It was used to measure the diameters of 100 fibres obtained from various parts of the nanoweb with the Image $\mathrm{J}$ program. The number mean and weight mean values were estimated using the following formulas: (1) and (2).

$$
\begin{gathered}
A_{n}=\frac{\sum n_{i} d_{i}}{\sum n_{i}} \text { (number average) } \\
A_{w}=\frac{\sum n_{i} d_{i}^{2}}{\sum n_{i} d_{i}} \text { (weight average) }
\end{gathered}
$$

The $A_{w} / A_{n}$ ratio was used to obtain the fibre uniformity coefficient as well as for the molar mass distributions. $A_{n}$ optimum value close to 1 indicates fibres of the same type in size [13]. Fibre diameter histogram was obtained by SPSS statistical program.

Lastly, FT-IR analysis was performed to determine the presence of PCT loaded microcapsules into the nanofiber structures.

\section{RESULTS AND DISCUSSION}

Microcapsule production was carried out by emulsion/solvent evaporation method under the optimum process parameters. SEM images of paracetamol loaded Eudragit RS 100/PVA microcapsules are shown in figure 1.
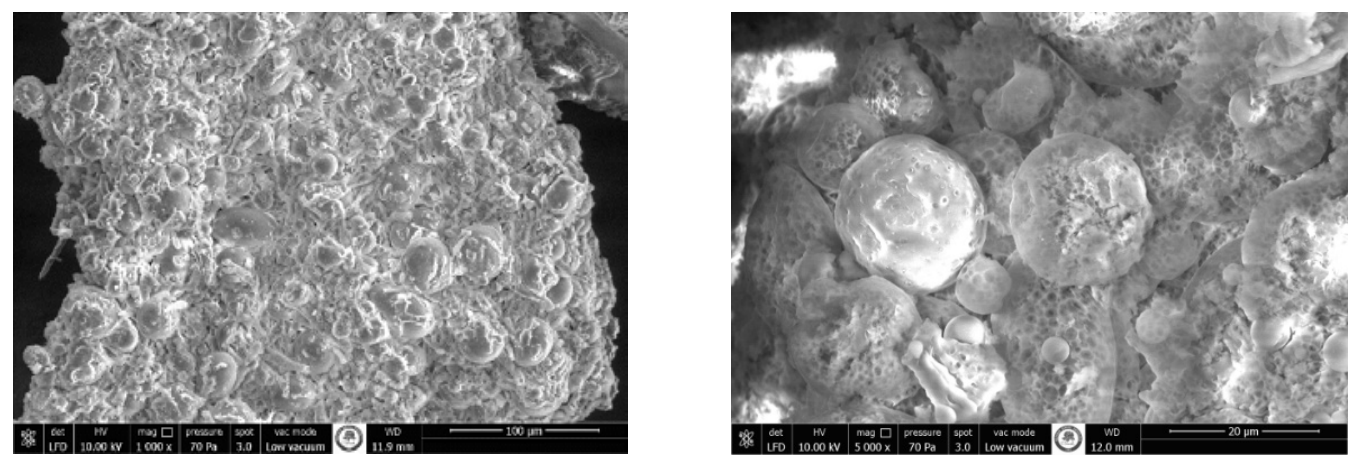

Figure 1. SEM images of PCT loaded Eudragit RS 100/PVA microcapsules (1.000x, 5.000x) 
As seen from the SEM images, PCT loaded Eudragit RS 100/PVA microcapsules have a partial spherical shape and also there are some cracks. Average microcapsule size is 9.81 $\mu \mathrm{m}$. Then, solution properties (conductivity, viscosity and surface tension) of PVA solutions include different concentrations of microcapsules, were measured. The results of solution properties are given in figure 2.

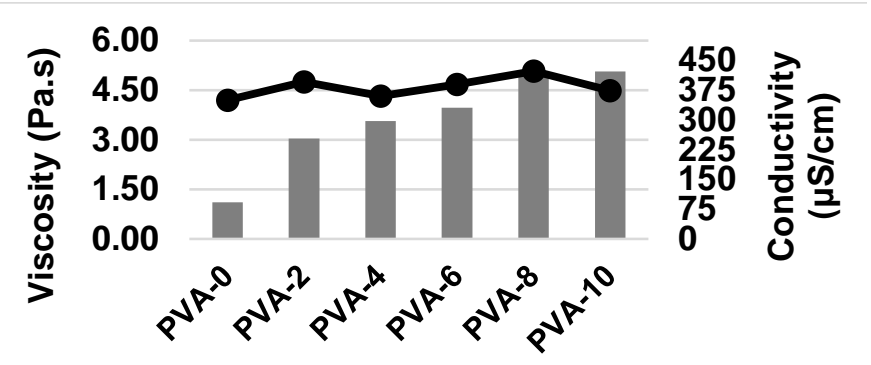

Viscosity (Pa.s) $\rightarrow$ Conductivity $(\mu \mathrm{S} / \mathrm{cm})$

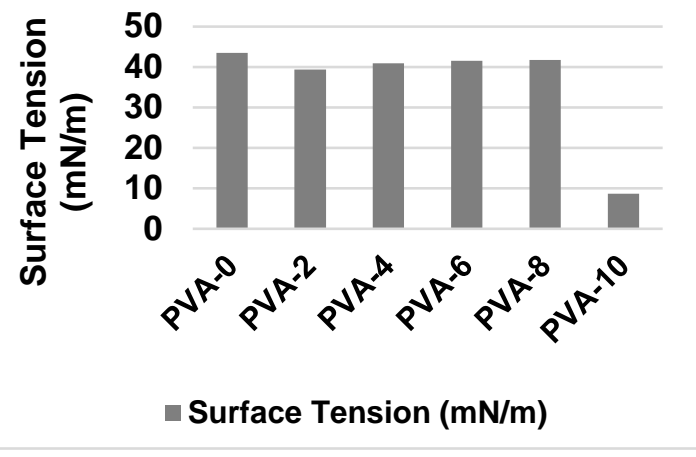

$b$

Figure 2. Solutions properties of PVA polymer solutions with different concentrations of microcapsules: a - viscosity and conductivity; b- surface tension

According to figure 2, viscosity increases with microcapsule concentration increasement while conductivity and surface tension were not significantly change except sample PVA-10. Surface tension decreased drastically at $10 \mathrm{wt} \%$ concentration of PCT loaded microcapsules (PVA-10).

Morphology of PVA nanofibers at various concentrations of PCT loaded microcapsules such as 0, 2, 4, 6, 8 and 10 wt\% were examined by SEM images (figure 3).
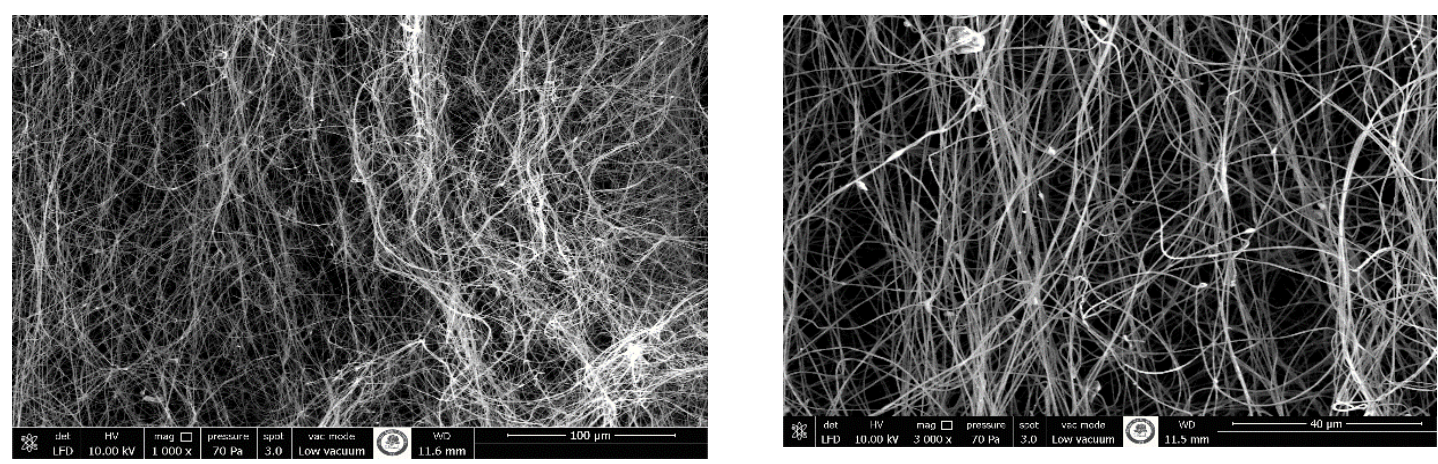

PVA0
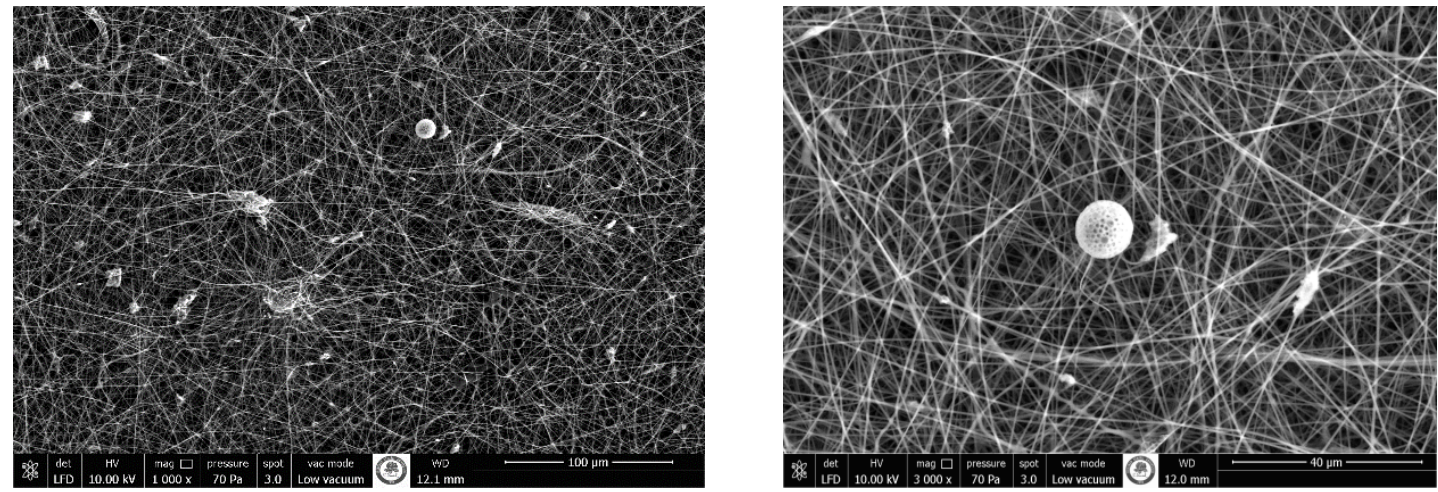

PVA-2 

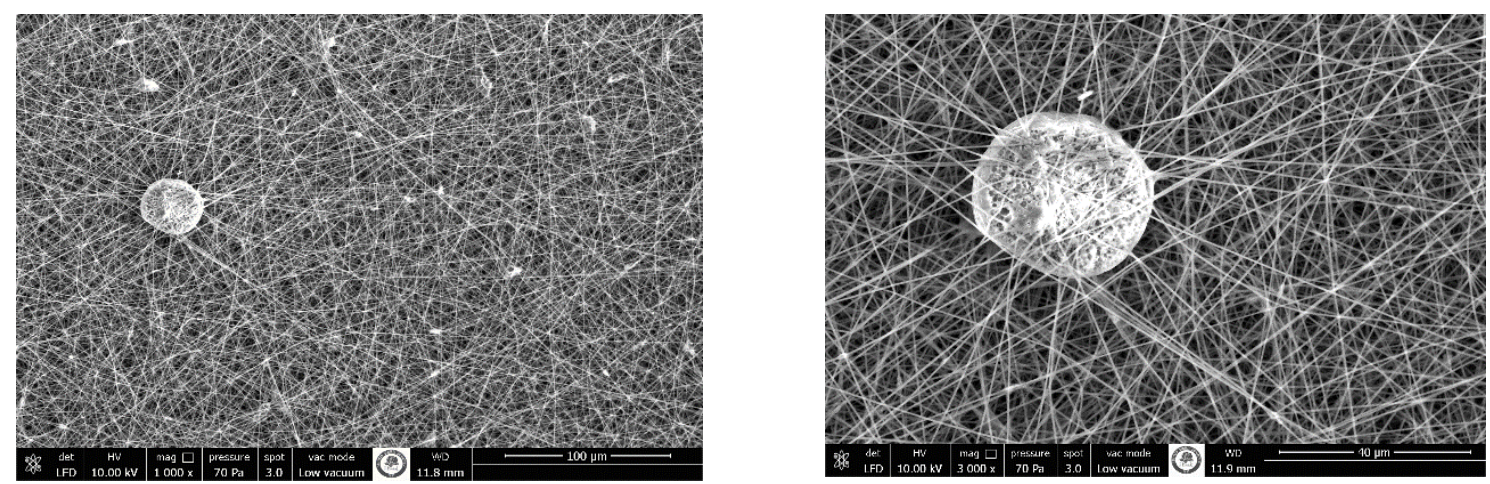

PVA-4
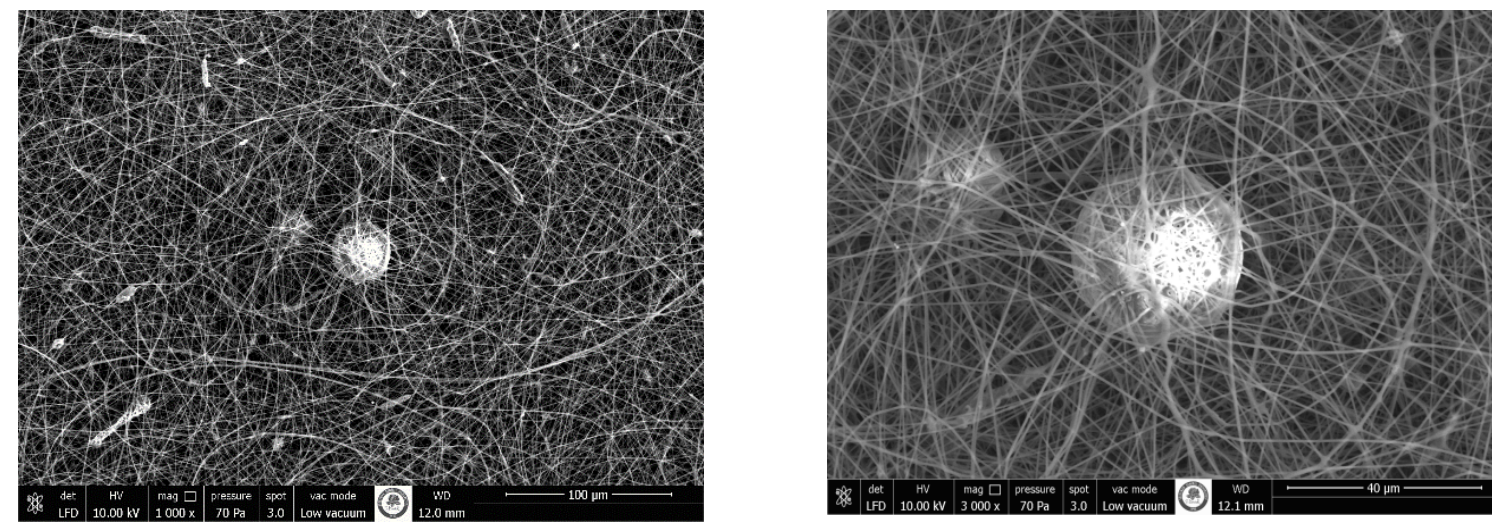

PVA-6
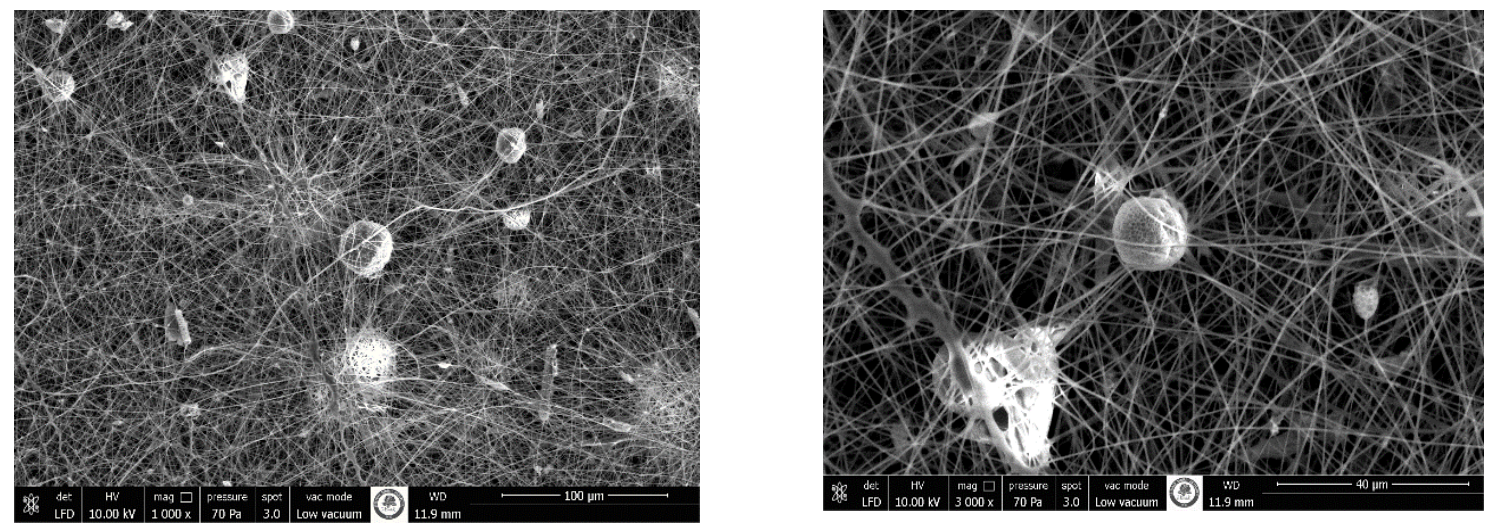

PVA-8
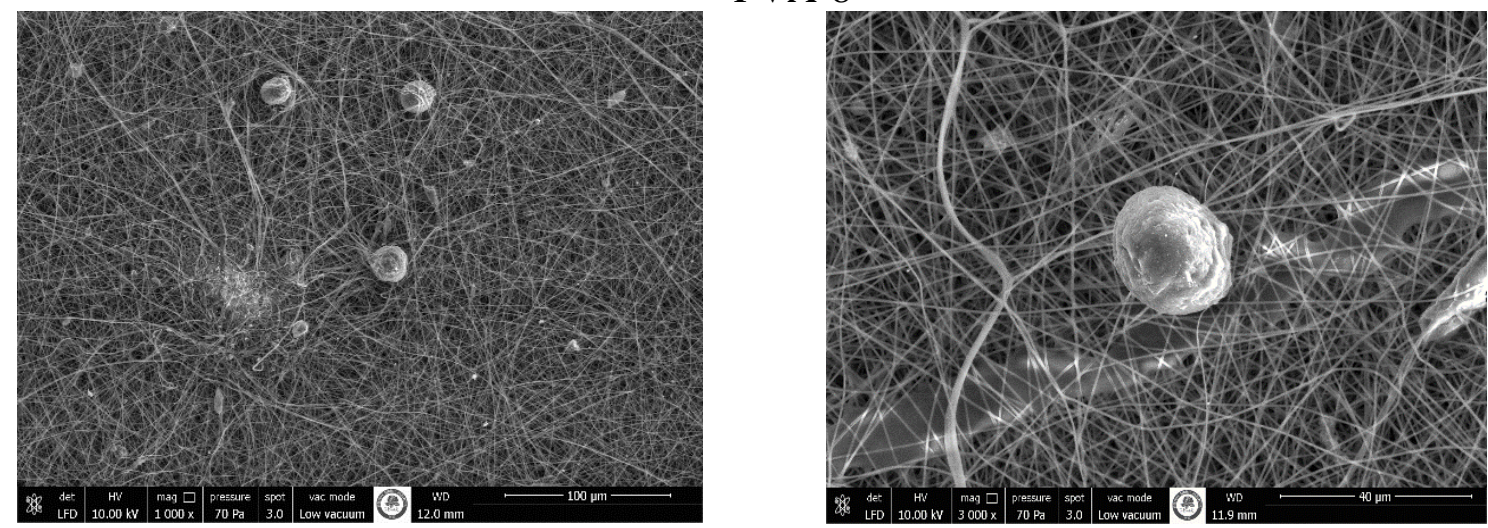

PVA-10

Figure 3. SEM images of PVA nanofibers with various concentrations of microcapsules $(1.000 \mathrm{x}, 3.000 \mathrm{x})$ 
As shown in the SEM images, PCT loaded microcapsules were successfully incorporated into the nanofibrous structure. Generally, quite fine, smooth and uniform nanofibers were obtained. PVA nanofibers diameter histogram is given in figure 4.

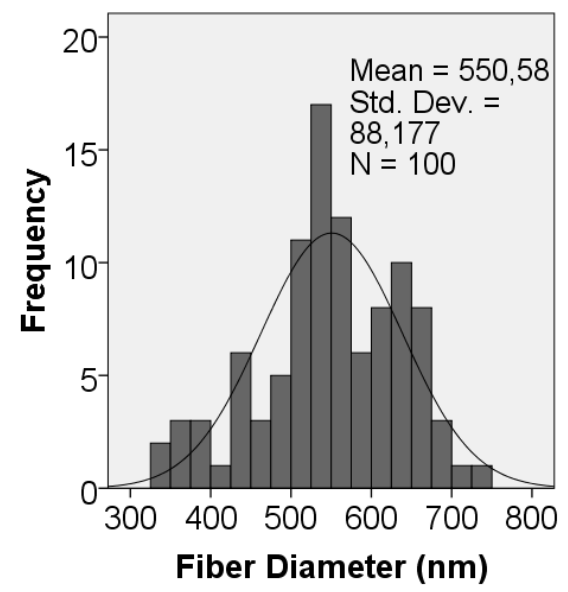

Figure 4. Electro spun PVA nanofiber diameter histogram

From the calculations; average fibre diameter is $550 \mathrm{~nm}$ and fibre diameter uniformity coefficient are 1.025. Unimodal histogram curve was obtained from the SPSS diagram. In addition, it is possible to say that fibre morphology (diameter, diameter uniformity) was not affected from the microcapsule concentration.

FT-IR spectroscopy confirmed the presence of PVA polymer and PCT loaded microcapsules in the chemical structures of the nanofibers (figure 5).

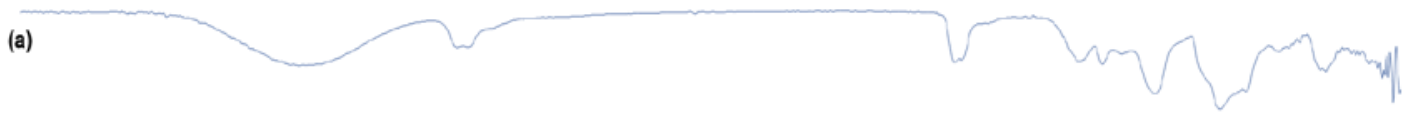

(b)

(c)

(d)

(e)

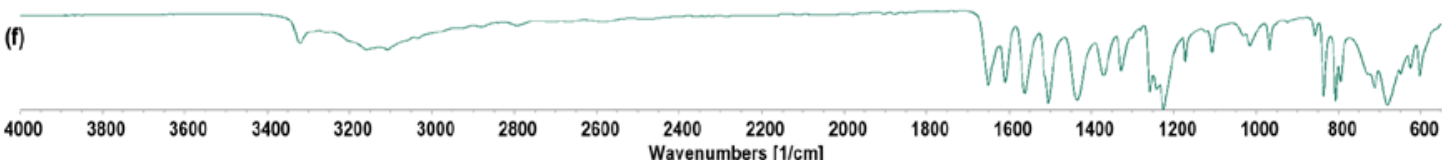

Figure 5. FT-IR spectra of: a - PVA-0 nanofibers; b- PVA-10 nanofibers; c- PVA polymers; d- PCT/PVA/Eudragit RS 100 microcapsules; e- Eudragit RS 100 polymers; f- PCT

The FT-IR spectrum of PVA demonstrates the primary peaks linked with PVA and PVA nanofibers quite clearly. For instance, the typical strong hydrogen bonded band occurred at approximately 2940-2912 $\mathrm{cm}^{-1}$ wavelength in the spectra of PVA polymer, PVA-0 and PVA-10 nanofibers. Because of the high hydrophilic forces, intramolecular and 
intermolecular hydrogen bonding is expected to occur among PVA chains. Another important absorption peak was confirmed at $1141 \mathrm{~cm}^{-1}$. This peak arises at $1243 \mathrm{~cm}^{-1}$ and $1245 \mathrm{~cm}^{-1}$ in the spectra of PVA-0 and PVA-10 nanofibers, respectively. The crystallinity of PVA is primarily responsible for this vibrational band, which is related to the carboxyl stretching band (C-O) [14]. The most intense peak in the spectrum, pure PCT has a peak at $1561 \mathrm{~cm}^{-1}$. These peaks are seen at $2922 \mathrm{~cm}^{-1}$ and $2853 \mathrm{~cm}^{-1}$ for PVA-10 nanofiber and $2925 \mathrm{~cm}^{-1}$ and $2854 \mathrm{~cm}^{-1}$ for microcapsule spectra [15]. The carbonyl stretching vibration of the ester group is responsible for the stretching bands of Eudragit RS 100 at $1143 \mathrm{~cm}^{-1}$ and $1237 \mathrm{~cm}^{-1}$. These stretching bands are attributed to $1173 \mathrm{~cm}^{-1}$ and $1243 \mathrm{~cm}^{-1}$ for PVA-10 nanofibers and to 1237 $\mathrm{cm}^{-1}$ and $1145 \mathrm{~cm}^{-1}$ for spectra of microcapsules [16,17].

\section{CONCLUSIONS}

This study was carried out for the production and characterization of PCT loaded microcapsules by solvent/emulsion method and PCT loaded microcapsule incorporation to the PVA nanofibers with various concentrations by electrospinning. Generally, partial spherical and some cracks shapes of capsules were synthesized and incorporate to the PVA nanofibers at various concentrations. The incorporation of PCT loaded microcapsules to the PVA nanofibers was verified with SEM images and FT-IR results. It is thought that this research results will be useful for the medical textile-based materials in future.

\section{REFERENCES}

[1] Eyüpoğlu, Ş., Kut, D., Microencapsulation technology and the use of microencapsulation technology in textile industry, In: Istanbul Commerce University Journal of Technologies and Applied Sciences, 2016, 15, 29, 9-28

[2] Kesici Güler, H., Bazı bitki ekstratlarının eldesi, mikrokapsülasyonu ve pamuklu kumaşa aplikasyonu, Master's Thesis, At: Institute of Natural and Applied Sciences Süleyman Demirel University, 2015

[3] Çimen, E., Possibilities of bring in new properties to woven fabrics by microencapsulation method, PhD thesis, At: Institute of Natural and Applied Sciences, Istanbul Technical University, 2007

[4] Reddy, Y., Dastagiri D., et al., Formulation and in vitro evaluation of antineoplastic drug loaded nanoparticles as drug delivery system, In: AJPP, 2013, 7, 23, 1592-1604, https://doi.org/10.5897/AJPP2013.3436

[5] Thakral, S., Thakral, N. K., Majumdar, D. K., Eudragit ${ }^{\circledR}:$ a technology evaluation. expert opinion on drug delivery, 2013, 10, 1, 131-149. https://doi.org/10.1517/17425247.2013.736962

[6] Pignatello, R., Amico, D., Chiechio, S., Spadaro, C., Puglisi, G., Giunchedi, P., Preparation and analgesic activity of eudragit rs100® microparticles containing diflunisal, In: Drug Deliv., 2001, 8, 1, 35-45, https://doi.org/10.1080/107175401300002748

[7] Bolourchian, N., Bahjat M., Design and in vitro evaluation of eudragit-based extended release diltiazem microspheres for once- and twice-daily administration: the effect of coating on drug release behaviour, In: Turkish J. Pharm. Sci., 2019, 16, 3, 340-347, https://doi.org/10.4274/tjps.galenos.2018.24861

[8] Selimoğlu, F., Quantitative analysis of combined pharmaceutical preparations containin paracetamol by UPLC method, PhD Thesis, At: Institute of Health Sciences, Ataturk University, 2013

[9] Heiskanen, H., Denifl, P., Pitkänen, et al., Effect of concentration and temperature on the properties of the microspheres prepared using an emulsion-solvent extraction proces, In: Adv. Powder. Technol., 2012, 23, 6, 779-786, https://doi.org /10.1016/j.apt.2011.10.007

[10] Hong, Y., Gao, C., Shi, et. al., Preparation of porous polylactide microspheres by emulsionsolvent evaporation based on solution induced phase separation, In: Polym. Adv. Technol., 2005, 16, 8, 622-627, https://doi.org/10.1002/pat.629 
[11] Yüksel, İ., Effect of Process Parameters on Morphology of Electrospun PVA Nanofibers, In: PAJES, 2009, 15, 3, 363-369

[12] Üstündağ, G. C., Karaca, E., Production of electrospun nanofibrous mat containing alginate and providing of water resistance with crosslinking, In: Textile and Engineering, 2009, 16, 75

[13] Cengiz, F., Jirsak, O., The effect of salt on the roller electrospinning of polyurethane nanofibers, In: Fibers and Polymers, 2009, 10, 2, 177-184

[14] Mansur, H.S., Oréfice, R.L., Mansur, A.A., Characterization of poly (vinyl alcohol)/poly (ethylene glycol) hydrogels and PVA-derived hybrids by small-angle X-ray scattering and FTIR spectroscopy, In: Polymer, 2004, 45, 21, 7193-7202

[15] Eğri, Ö., Erdemir, N., Production of Hyperivum Perforatum Oil-Loaded Membranes For Wound Dressing Material And in Vitro Tests, Artificial Cells, In: Nanomedicine and Biotechnology An International Journal, 2019, 1404-1415

[16] Park, J.M., Park, S.J., Preparation and characterization of water-soluble microcapsule for sustained drug release using Eudragit RS 100, In: Macromolecular Research, 2010, 18, 12, 1191-1194

[17] Behera, B.C., Sahoo, S. K., Dhal, S., Barik, B.B., Gupta, B.K., Characterization of glipizideloaded polymethacrylate microspheres prepared by an emulsion solvent Evaporation Method, In:

Trop. J. Pharm. Res., 2008, 7, 1, 879-885, https://doi.org/10.4314/tjpr.v7i1.14672 